\title{
Studi Interaksi Air Tanah Dangkal dan Air Sungai di Sepanjang Daerah Aliran Kali Garang Semarang Menggunakan Isotop Stabil $\delta^{18} O$ dan $\delta^{2} H$
}

\section{Interaction Study of Shallow Groundwater and River Water along Kali Garang Semarang Flow Area Using Stable Isotopes of $\delta^{8}$ Oand $\delta^{2} H$}

\author{
Rismah Taufik Andihutomo ${ }^{1}$, Satrio $^{2}$, Rasi Prasetio ${ }^{2 *}$, Agus Budhie Wijatna ${ }^{1}$ \\ ${ }^{1}$ Jurusan Teknik Fisika UGM, Jl. Grafika 2, Yogyakarta 55281 \\ ${ }^{2}$ Pusat Aplikasi Isotop dan Radiasi BATAN, Jl. Lebak Bulus Raya No. 49, Jakarta 12440 \\ *E-mail: rasi_p@batan.go.id
}

Naskah diterima: 14 Februari 2017, direvisi: 18 Mei 2017, disetujui: 31 Mei 2017

\begin{abstract}
ABSTRAK
Penelitian mengenai interaksi airtanah dangkal dengan air sungai Kali Garang di Semarang, Jawa Tengah, menggunakan parameter isotop ${ }^{18} \mathrm{O}$ dan ${ }^{2} \mathrm{H}$ telah dilakukan. Sebanyak 16 sampel air tanah dangkal dan 3 sampel air sungai diambil untuk analisis kandungan isotop stabil $\delta^{18} \mathrm{O}$ dan $\delta^{2} \mathrm{H}$ menggunakan alat Liquid Water Isotope Analyzer LGR DLT-100. Hasil analisis memperlihatkan adanya dua asal daerah masukan air: daerah pertama memiliki kandungan isotop $\delta^{18} \mathrm{O}$ antara $-9,41 \%$ hingga-8,5 \%o dan $\delta^{2} \mathrm{H}$ antara $-58,2 \%$ hingga $-51,6 \%$; daerah kedua memiliki kandungan isotop $\delta^{18} \mathrm{O}$ dan $\delta^{2} \mathrm{H}$ masing-masing -7,15 \%o dan -41,55 \%o. Dengan demikian, hasil tersebut mengindikasikan bahwa sampel-sampel air pertama berasal dari elevasi yang relatif lebih tinggi jika dibandingkan dengan asal sampel air kedua, namun keduanya tidak mengalami interaksi dengan air sungai. Sedangkan sampel air tanah lainnya menunjukkan bahwa satu sampel (R4) memiliki interelasi berupa pencampuran dengan air sungai dan dua sampel lainnya (L1 dan R1) mengalami pencampuran dengan air asin atau air laut.
\end{abstract}

Kata kunci: studi interaksi, air tanah dangkal, isotop stabil, Sungai Kali Garang Semarang

\begin{abstract}
A study related to shallow groundwater interaction with Kali Garang River water in Semarang, Central Java using stable isotopes of ${ }^{18} \mathrm{O}$ and ${ }^{2} \mathrm{H}$ has been conducted. As much as 16 groundwater and 3 river water samples were taken for stable isotopes $\delta^{18} \mathrm{O}$ and $\delta^{2} \mathrm{H}$ analysis using Liquid water isotope analyzer LGR DLT-100. The results of analysis shows that there are two area of water recharge origin: the first area contains $\delta^{18} \mathrm{O}$ isotope ranging between $-9.41 \%$ to $-8.5 \%$ and $\delta^{2} H$ between $-58.2 \%$ to $-51.6 \%$; the second area contains isotopes of $\delta^{18} \mathrm{O}$ and $\delta^{2} \mathrm{H}-7.15$ and $-41.55 \%$, respectively. Thus, these results indicate that the first water samples originate from a higher elevation than the origin of the second water sample, but both of them have no interrelation with river water. Whereas, other groundwater samples show that the sample (R4) has interrelation (i.e. mixing) with the river water and two other samples (L1 and R1) have interrelation with salty water or seawater.
\end{abstract}

Keywords: interrelation study, shallow groundwater, stable isotope, Kali Garang River Semarang 


\section{PENDAHULUAN}

Sungai Kali Garang berasal dari Pegunungan Ungaran, mengalir ke Laut Jawa melalui Kota Semarang [1]. Di sepanjang daerah aliran sungai (DAS) Kali Garang, terdapat pemukiman dan beberapa kawasan industri yang semakin berkembang sehingga dapat berpengaruh terhadap kualitas air sungai [2][3]. Selain itu, berbagai kegiatan lain seperti pertanian dan perkebunan, peternakan juga berpotensi mencemari sungai Kali Garang [4].

Penduduk di sepanjang DAS Kali Garang diketahui memiliki sumur gali dengan kedalaman bervariasi antara 3-18 m yang digunakan untuk kegiatan sehari-hari. Dari informasi penduduk yang bermukim di sepanjang DAS Garang, air sumurnya diketahui tidak pernah kering, tetapi volume airnya berubah sesuai musim. Namun demikian, kualitas airnya tidak terlalu baik untuk dikonsumsi. Tingginya resiko pencemaran air Kali Garang memerlukan sistem deteksi agen pencemar air sebagai penanda awal pencemaran [5]. Adanya fenomena hubungan antara air sungai dengan air sumur penduduk memungkinkan terjadinya pencemaran pada air sumur penduduk di sepanjang DAS Garang.

Berdasarkan latar belakang tersebut, maka perlu dilakukan penelitian hubungan antara air tanah dengan air sungai di sepanjang DAS Garang. Melalui pendekatan isotop stabil ${ }^{18} \mathrm{O}$ dan ${ }^{2} \mathrm{H}$ dapat diketahui hubungan antara air tanah yang digunakan penduduk dengan air sungai di sepanjang daerah aliran sungai (DAS) Garang, Semarang [6].

\section{METODOLOGI}

Pengambilan sampel

Isotop stabil ${ }^{18} \mathrm{O}$ dan ${ }^{2} \mathrm{H}$ sangat peka terhadap proses fisika seperti penguapan, oleh karena itu untuk mencegahnya, pengambilan sampel air dilakukan sebagai berikut: Sampel air sebanyak $20 \mathrm{ml}$ dimasukkan ke dalam botol kedap udara dengan cara mendekatkan botol terhadap sumber air atau memasukkannya ke dalam sumber air. Gelembung udara dalam botol harus dihindari untuk mencegah adanya penguapan atau evaporasi [7][8].

\section{Analisis isotop stabil ${ }^{18} \mathrm{O} \operatorname{dan}^{2} \mathrm{H}$}

Analisis kandungan isotop ${ }^{18} \mathrm{O}$ dan ${ }^{2} \mathrm{H}$ dilakukan menggunakan alat liquid water isotope analyzer LGR (Los Gatos Research) DLT-100 seperti dapat dilihat pada Gambar 1. Hasil perhitungan analisis isotop ${ }^{18} \mathrm{O}$ dan ${ }^{2} \mathrm{H}$ mengacu kepada standar internasional yaitu SMOW (Standard Mean Ocean Water) yang memiliki nilai ${ }^{18} \mathrm{O}$ dan ${ }^{2} \mathrm{H}$ sebesar $0 \%$ secara definitif [9][10]. Hasil perhitungan analisis rasio ${ }^{18} \mathrm{O} /{ }^{16} \mathrm{O}$ dan ${ }^{2} \mathrm{H} /{ }^{1} \mathrm{H}$ dinyatakan dalam rasio relatif $(\delta)$ dengan satuan permil sebagai berikut [11][12]:

$$
\delta=\frac{\left[\frac{{ }^{18} O}{{ }^{16} O}\right]_{\text {sample }}}{\left[\frac{{ }^{18} O}{{ }^{16} O}\right]_{\text {tan dard }}} \times 1000 \%
$$




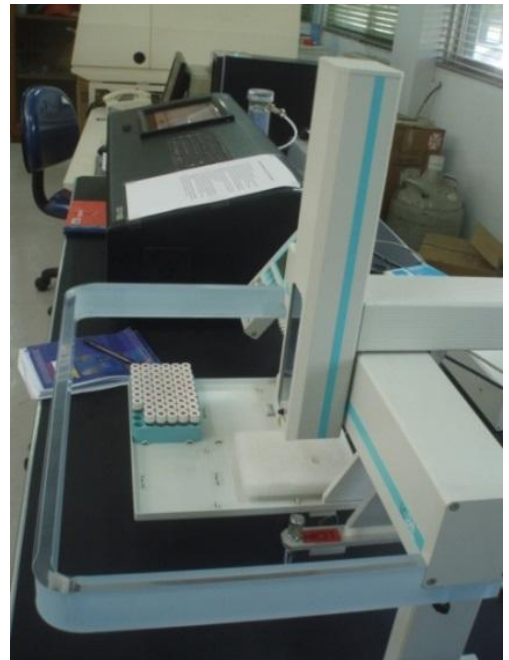

Gambar 1. Liquid water isotope analyzer LGRDLT100 .

\section{HASIL DAN PEMBAHASAN}

Penelitian interaksi air tanah dan air Kali Garang yang dilakukan pada musim kering, yaitu sekitar bulan Mei 2015 untuk meminimalkan pengaruh air hujan terhadap sampel air tanah dan air sungai yang akan diteliti kandungan isotopnya. Sejumlah sampel air tanah dangkal diambil di beberapa lokasi sepanjang DAS Garang. Sedangkan sampel air sungai diambil di bagian hulu, tengah, dan hilir. Data pada Tabel 1 berikut memperlihatkan lokasi pengambilan sampel dari sumur-sumur penduduk dan air sungai di beberapa titik pengambilan di sepanjang DAS Garang.

Peta lokasi pengambilan sampel dapat dilihat pada Gambar 2 berikut ini. Secara geografis, DASGarang terletak di antara $110^{\circ}$ $15^{\prime} 43^{\prime} \mathrm{BT}-110^{\circ} 30^{\prime} 37^{\prime} \mathrm{BT}$ dan $6^{\circ} 54^{\prime} 49^{\prime \prime}$ LS-7 ${ }^{\circ}$ 11' 51" LS [13]. Secaraadministratif DAS Kali Garang meliputi tiga kabupaten dan satu kota madya, yaitu: Kabupaten Demak, wilayah Kabupaten Kendal, wilayah Kabupaten Semarang serta wilayah Kotamadya Semarang. Hasil analisis isotop stabil $\delta^{18} \mathrm{O}$ dan $\delta^{2} \mathrm{H}$ dapat dilihat pada tabel 2 .

Tabel 1.Koordinat lokasi pengambilan sampel.

\begin{tabular}{ccccc}
\hline \multirow{2}{*}{ No. } & Kode & \multicolumn{2}{c}{ Koordinat (UTM) } & $*$ *MAT (m) \\
\cline { 3 - 4 } & Sampel & X & Y & \\
\hline 1 & L1 & 433776,98 & 9228862,17 & 0,36 \\
2 & L2 & 433778,15 & 9227943,97 & 0,76 \\
3 & L3 & 433913,76 & 9227471,22 & 6,14 \\
4 & L4 & 433853,46 & 9226632,79 & 3,06 \\
5 & L5 & 433253,08 & 9225852,01 & 5,23 \\
6 & L6 & 432716,47 & 9225599,50 & 5,67 \\
7 & L7 & 432291,58 & 9224373,65 & 0,00 \\
8 & R1 & 434185,05 & 9228887,25 & 2,21 \\
9 & R2 & 434044,97 & 9228045,65 & 0,00 \\
10 & R3 & 434067,04 & 9227578,90 & 0,00 \\
11 & R4 & 433926,83 & 9226359,57 & 1,29 \\
12 & R5 & 433388,20 & 9225760,06 & 5,01 \\
13 & R6 & 432670,56 & 9225510,39 & 6,38 \\
14 & R7 & 432445,03 & 9224343,15 & 0,00 \\
15 & L8 & 432746,34 & 9223861,40 & 3,56 \\
16 & R8 & 432740,09 & 9223947,38 & 3,41 \\
17 & SU & 433878,09 & 9228982,06 & - \\
18 & ST & 433841,49 & 9226396,31 & - \\
19 & SS & 432365,30 & 9224309,26 & - \\
\hline NAT: M & Air Tanah & & & \\
\hline
\end{tabular}

*MAT: Muka Air Tanah 


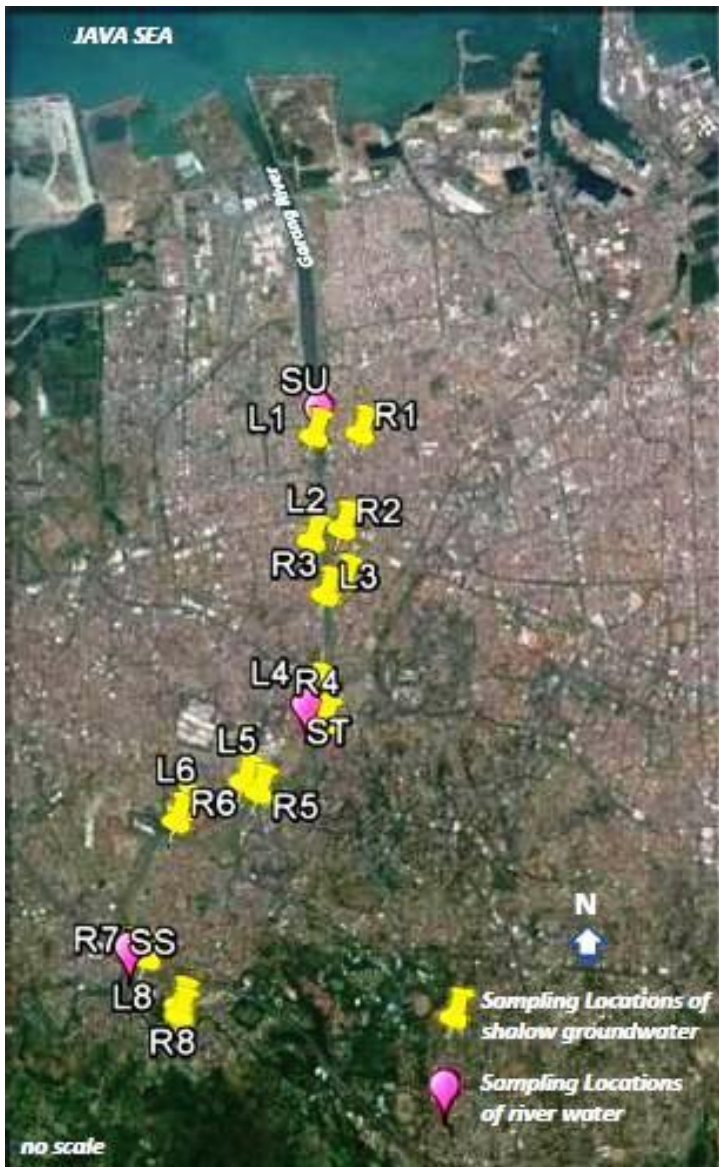

Gambar 2. Lokasi pengambilan sampel.

\begin{tabular}{cccc}
\multicolumn{3}{c}{ Tabel 2. Hasil analisis isotop stabil $\delta^{18} \mathrm{O}$ dan $\delta^{2} \mathrm{H}$} \\
\hline No. & Kode Sampel & $\delta^{18} \mathrm{O}(\%)$ & $\delta^{2} \mathrm{H}(\%)$ \\
\hline 1 & L1 & $-4,13$ & $-1,40$ \\
2 & L2 & $-51,86$ & $-8,56$ \\
3 & L3 & $-55,00$ & $-8,87$ \\
4 & L4 & $-41,55$ & $-7,15$ \\
5 & L5 & $-58,20$ & $-9,41$ \\
6 & L6 & $-54,47$ & $-8,97$ \\
7 & L7 & $-55,15$ & $-9,05$ \\
8 & R1 & 0,08 & $-1,22$ \\
9 & R2 & $-54,30$ & $-8,74$ \\
10 & R3 & $-55,11$ & $-8,73$ \\
11 & R4 & $-30,94$ & $-4,50$ \\
12 & R5 & $-52,05$ & $-8,50$ \\
13 & R6 & $-55,89$ & $-9,15$ \\
14 & R7 & $-55,13$ & $-8,83$ \\
15 & L8 & $-30,60$ & $-4,99$ \\
16 & R8 & $-51,61$ & $-8,61$ \\
17 & SU & $-32,87$ & $-4,83$ \\
18 & ST & $-40,42$ & $-6,33$ \\
19 & SS & $-51,65$ & $-8,12$ \\
\hline
\end{tabular}

Hasil analisis isotop stabil ${ }^{18} \mathrm{O}$ dan ${ }^{2} \mathrm{H}$ selanjutnya diplotkan pada grafik hubungan ${ }^{2} \mathrm{H}$ terhadap ${ }^{18} \mathrm{O}$ seperti Gambar 3. Air hujan atau air meteorik cenderung memiliki kandungan isotop stabil $\delta^{18} \mathrm{O}$ dan $\delta^{2} \mathrm{H}$ yang lebih miskin (depleted) pada daerah lintang yang lebih tinggi [14]. Fenomena ini juga terjadi saat kedua isotop stabil tersebut bergerak jauh ke dalam daratan. Dengan alasan ini, hasil plot kedua isotop menghasilkan kemiringan yang sedikit berbeda dan dikenal dengan garis meteorik lokal ataulocal meteoric water line (LMWL) [15]. Garis meteorik lokal untuk wilayah Semarang diambil berdasarkan penelitian terdahulu memenuhi persamaan garis $\delta^{2} \mathrm{H}=$ $8,55 \delta^{18} \mathrm{O}+16,76 \%$ [16].

Berdasarkan Gambar 3 tersebut terlihat bahwa terdapat 4 kelompok karakteristik air tanah di sepanjang DAS Garang:

1. Grup I: sebagian besar sampel air pada grup ini memiliki nilai isotop stabil $\delta^{2} \mathrm{H}$ dan $\delta^{18} \mathrm{O}$ paling depleted dibanding sampel air tanah lainnya. Ini mengindikasikan bahwa sampel-sampel tersebut tidak berhubungan dengan air Kali Garang dan berasal dari elevasi paling tinggi. Lokasi ini merupakan bagian dari daerah tangkapan air untuk daerah Semarang. Disamping itu, air Kali Garang di lokasi sampel SS masih memiliki karakter sebagai air meteorik.

2. Grup II: sampel dengan kode L4 ini berasal dari elevasi yang lebih rendah dari grup I dan masih memiliki karakter sebagai air meteorik serta tidak berhubungan dengan air Kali Garang.

3. Grup III: sampel dengan kode L8 berada diantara garis meteorik dan garis air Kali Garang, namun lebih lebih dominan dekat dengan garis air Kali Garang. Ini mengindikasikan bahwa sampel air tanah 
L8 ada percampuran dengan air sungai yang berasal dari Kali Garang. Sedangkan sampel dengan kode R4 tepat berada di garis air Kali Garang yang mengindikasikan bahwa sampel air dari lokasi tersebut merupakan air yang berasal dari Kali Garang.

4. Grup IV: sampel dengan kode 7R dan 7L yang letaknya paling utara memilik nilai isotop stabil ${ }^{2} \mathrm{H}$ dan ${ }^{18} \mathrm{O}$ paling kaya atau enrich yang mengindikasikan bahwa sampel tersebut terkontaminasi air asin yang diduga berasal dari air laut sebagai akibat pengaruh fenomena pasang-surut air laut.

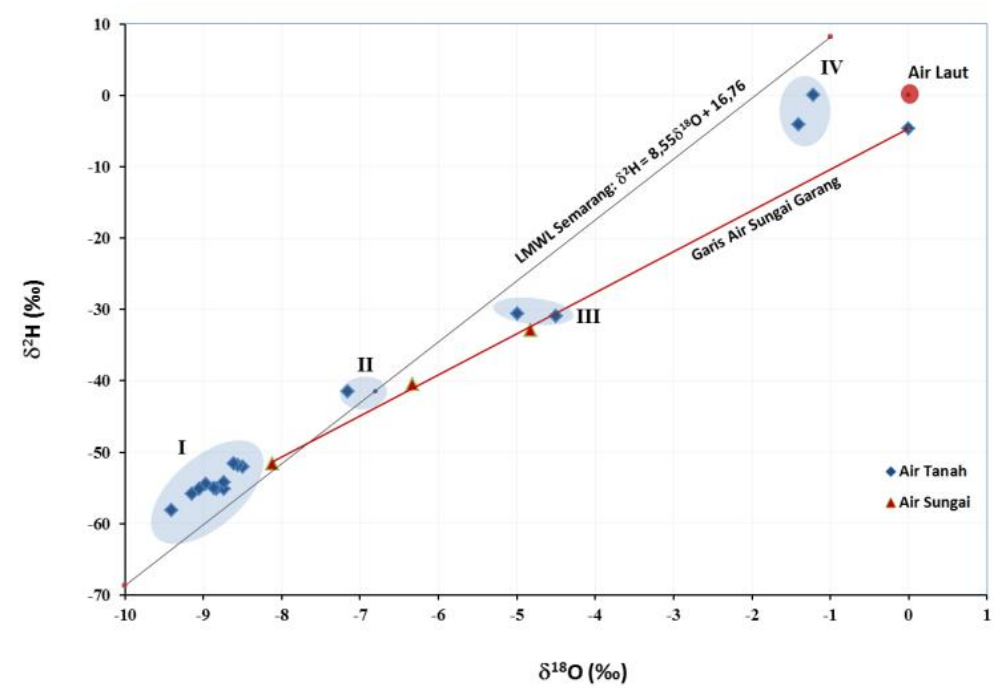

Gambar 3. Grafik hubungan isotop $\delta^{2} \mathrm{H}$ vs $\delta^{18} \mathrm{O}$ air tanah dan air Kali Garang.

\section{KESIMPULAN}

Berdasarkan pembahasan di atas, maka dapat disimpulkan bahwa sebagian besar sampel air tanah masih memiliki karakter sebagai air yang berasal dari air meteorik. Dua sampel, yaitu L8 dan R4 mengalami percampuran dengan air Kali garang. Sedangkan dua sampel lainnya yang terletak paling utara, yaitu 7R dan 7L mengalami percampuran dengan air asinyang diduga berasal air laut yang tercampur dengan air sungai pada saat pasang. Disamping itu, sampel air Kali Garang yang berasal dari lokasi paling selatan (sampel kode SS) masih memiliki karakter sebagai air meteorik.

\section{UCAPAN TERIMA KASIH}

Penulis mengucapkan terimakasih kepada analis isotop stabil ${ }^{18} \mathrm{O}$ dan ${ }^{2} \mathrm{H}$ di laboratorium
Hidrologi, Bidang Industri dan Lingkungan, Pusat Aplikasi Isotop dan Radiasi-BATAN.

\section{DAFTAR PUSTAKA}

[1] G. Asocadewi, W. Oktiawan, and M. Hadiwidodo, "Penentuan Status mutu Air Dengan Menggunakan Metode Indeks Pencemaran (Studi Kasus: Sungai Garang, Semarang)," J. Tek. Lingkung. Undip, vol. 4, no. 2, pp. 1-7, 2015.

[2] R. Susanti, D. Mustikaningtyas, and F. A. Sasi, "Analisis Kadar Logam Berat pada Sungai di Jawa Tengah," Sainteknol, vol. 12, no. 1, pp. 3540, 2014.

[3] J. R. Putri, E. Sutrisno, and I. W. Wardana, "Pengaruh Pengelolaan Limbah Domestik Dengan Peningkatan Jumlah Septic Tank Terhadap Bebab Cemaran BOD Di Kali Semarang Menggunakan Program Qual2E," $J$. Tek. Lingkung. Undip, vol. 3, no. 2, pp. 1-9, 2014.

[4] B. Marlena, S. B. Sasongko, and D. Sutrisnanto, "Kajian Pengelolaan Sub DAS Garang Hulu Terhadap Kualitas Air Sungai," in Prosiding Seminar Nasional Pengelolaan Sumberdaya 
Alam dan Lingkungan, Undip Semarang, 2012, pp. 23-29.

[5] N. K. Dewi, Perdhana, and Yuniastuti, "Paparan Seng di Perairan Kaligarang Terhadap Ekspresi Zn-Thionein dan Konsentrasi Seng pada Hati Ikan Mas," J. MIPA Unnes, vol. 35, no. 2, pp. 108-115, 2012.

[6] Y. Yi, J. J. Gibson, L. W. Cooper, J.-F. Helie, S. J. Birks, J. W. McClelland, R. M. Holmes, and B. J. Peterson, "Isotopic signals ( $18 \mathrm{O}, 2 \mathrm{H}, 3 \mathrm{H}$ ) of six major rivers draining the pan-Arctic watershed," Global Biogeochem. Cycles, vol. 26, no. 1, Mar. 2012.

[7] Satrio, Hendarmawan, M. Sapari, and E. Ristin, "Karakteristik Air Tanah Dangkal Kota Semarang pada Musim Penghujan Berdasarkan Pendekatan Isotop Stabil $(18 \mathrm{O}, 2 \mathrm{H})$ dan Kimia Air," J. Ilm. Apl. Isot. dan Radiasi, vol. 11, no. 1, pp. 73-86, 2015.

[8] Satrio and P. Sidauruk, "Studi Daerah Imbuh Sistem Air Sungai Bawah Tanah GunungkidulYogyakarta Menggunakan Isotop Stabil 180 dan 2H," J. Ilm. Apl. Isot. dan Radiasi, vol. 12, no. 1, 2015.

[9] S. T. Allen, J. R. Brooks, R. F. Keim, B. J. Bond, and J. J. McDonnell, "The role of pre-event canopy storage in throughfall and stemflow by using isotopic tracers," Ecohydrology, vol. 7, no. 2, pp. 858-868, Apr. 2014.

[10] B. Sharma, R. Singh, P. Singh, D. P. Uniyal, and R. Dobhal, "Water Resource Management through Isotope Technology in Changing Climate," Am. J. Water Resour., vol. 3, no. 3, pp. 86-91, 2015.
[11] S. M. Yidana, "The Stable Isotope Characteristics of Groundwater in the Voltaian Basin - An Evaluation of the Role of Meteoric Recharge in the Basin," J. Hydrogeol. Hydrol. Eng., vol. 2, no. 2, pp. 1-10, 2013.

[12] S. B. Muhammad and U. Sadiq, "Analysis of Stable Isotopic Composition of Precipitation in Katsina State In Nigeria As An Indication of Water Cycle," Adv. Phys. Theor. Appl., vol. 33, pp. 28-34, 2014.

[13] Cahyadi, A. Yananto, M. Sufwandika, and H. Nugraha, "Analisis Pengaruh Perubahan Penggunaan Lahan Terhadap Retensi Potensial Air Tanah pada Kejadian Hujan Sesaat (Studi Kasus Perubahan Penggunaan Lahan di DAS Garang Jawa Tengah)," in Seminar Nasional Informatika, UPN Veteran Yogyakarta, 2012, pp. E1-E7.

[14] O. Mustafa, B. Merkel, and S. M. Weise, "Assessment of Hydrogeochemistry and Environmental Isotopes in Karst Springs of Makook Anticline, Kurdistan Region, Iraq," Hydrology, vol. 2, no. 2, pp. 48-68, 2015.

[15] M. Gaj, M. Beyer, P. Koeniger, H. Wanke, J. Hamutoko, and T. Himmelsbach, "In situ unsaturated zone water stable isotope measurements in semi-arid environments: a soil water balance," Hydrol. Earth Syst. Sci., vol. 20, no. 2, pp. 715-731, Feb. 2016.

[16] M. Susana. and D. Harnandi, "Penelitian Hidrogeologi Daerah Imbuhan Air Tanah Dengan Metode Isotop dan Hidrokimia di Cekungan Air Tanah Semarang-Demak Propinsi Jawa Tengah," Bandung, 2007. 